The IJA is a peer-reviewed open-access, electronic journal, freely available without charge to users

Produced by the AquacultureHub non-profit Foundation Sale of IJA papers is strictly forbidden

\title{
Histological study on development of the digestive system of longfin batfish (Platax teira)
}

\section{Chen Zeng ${ }^{a, c}$ Bao-Suo Liu, ${ }^{a, e}$ Ke-Cheng Zhu ${ }^{a, e}$ Hua-Yang Guo ${ }^{a, e}$ Liang Guo $^{a, e}$ Nan Zhang ${ }^{a, e}$ Bo Liu ${ }^{a, b}$ Zhi-Yong Wang ${ }^{b}$ Dian-Chang Zhang ${ }^{a, d, e, f *}$}

\author{
${ }^{a}$ Key Laboratory of South China Sea Fishery Resources Exploitation and Utilization, Ministry of \\ Agriculture and Rural Affairs; South China Sea Fisheries Research Institute, Chinese Academy of \\ Fishery Sciences, 510300, Guangzhou, Guangdong Province, China
}

${ }^{b}$ Key Laboratory of Healthy Mariculture for the East China Sea, Ministry of Agriculture and Rural Affairs, Jimei University, Xiamen,361021, China

${ }^{c}$ College of Fisheries, Tianjin Agricultural University, 300392, Tianjin, China

d Southern Marine Science and Engineering Guangdong Laboratory (Guangzhou), 511458, Guangdong Province, China

e Guangdong Provincial Engineer Technology Research Center of Marine Biological Seed Industry, Guangzhou, Guangdong Province, China

${ }^{f}$ Tropical Aquaculture Research and Development Center, South China Sea Fisheries Research Institute, Chinese Academy of Fishery Sciences, Sanya, 572018, China

Keywords: Platax teira, Histology, Ontogeny, Digestive system

\begin{abstract}
The ontogeny of the digestive tract in Platax teira was studied by means of optical microscopy from hatching to 30 days post-hatching. Collect fertilized eggs from P. teira broodstock, fertilize the eggs to hatch in hatching net bags, and rear the larvae in higher-place ponds. Observe the morphology and structure of the digestive tract of larvae 1-30 days post-hatching using tissue slicing technique. The results showed that the oral cavity of the larvae was closed and had not yet begun to differentiate at 1 day post-hatching. Its digestive tract was close to the abdominal wall, and the yolk sac was completely dyed dark red. At 4 days post-hatching, the oropharyngeal cavity, esophagus, and stomach of the larvae had been communicated, and their oral cavity opened and food intake begins, entering the mixed period of endogenous nutrition and exogenous nutrition. Thereafter, the yolk sac gradually decreased to disappear, the esophagus, stomach, and intestines continued to differentiate, and their functions gradually improved. During 25-30 days post-hatching, the structure of the digestive tract of the larvae didn't change much. Due to the increase in the size of the larvae, most changes in the digestive system are related to the complexity of the tissues and the size of the organs. Specifically, the number of mucosal folds and cells in the esophagus and intestine increases, and the gastric glands and pits in the stomach increase. The number of mucous membrane folds, mucosal epithelial cells and gastric glands in the digestive tract increase with the growth of the larvae, indicating that the development of the digestive system of P. teira is consistent with the growth of larvae, morphological development, feeding, metabolism and other functions consistently, its developmental stage is also adapted to the stages of the early development stage of $P$. teira.
\end{abstract}

* Corresponding author: Dr. Dian-Chang Zhang. 231 Xingang Road West, Haizhu District, Guangzhou City, Guangdong Province, 510300, PR China. E-mail address:

zhangdch@scsfri.ac.cn; Phone: +86 02089108316; fax: +86 02089022702 


\section{Introduction}

Longfin batfish, Platax teira, also known as the long bat or batfish, belongs to Platax, Ephippidae, and Perciformes, is a kind of marine fish living near the shore in tropical and temperate regions. This species is native to India and occurs in the eastern Pacific, from the Red Sea and East Africa to Papua New Guinea, north to Ryukyu, and south to Australia, New Zealand and Melanesia (Bai, 2009; Golani et al., 2011). P. teira is one of the most important fin fish species in Asian aquaculture (Leu., 2018). P. teira is an omnivorous fish that prefers meat. It has a steep head, a small and round mouth, and large eyes. The body is flat and slightly rounded. The body color is separated by black and white, and the side line of the body is curved. The juveniles have 2-3 black horizontal bands on their sides. The dorsal, ventral and anal fins are elongated and sickle-shaped, and the adult fins become shorter. The caudal fin is double concave. $P$. teira grows rapidly, young fish have a beautiful shape and can be used as ornamental fish, and the meat quality of adult fish is delicious, with a high economic value and nutritional value (Liao, 2018). Adult fish grow fast, and in eight months, this fish can grow to about a catty, meeting the requirements of the market.

The food ingested by the fish is digested and absorbed by the digestive system, thereby maintaining its vital life activities such as growth, development and reproduction. Therefore, the structure of the digestive system determines the diet of fish. The histological development of the digestive system has been constantly used as a histological biomarker to estimate the nutritional status of fish at early life stages of development (Gisbert et al., 2008, 2013 and 2014). A large number of studies have shown that studies on the occurrence of digestive tract biological organs in specific fish can better understand their function and nutritional physiology (Lazo et al., 2011; Cuenca-Soria et al., 2013; Gisbert et al., 2014). Therefore, the study of the morphological and functional changes during the early individual development of special fish can help improve the breeding technology of this species of juvenile fish(Portella et al., 2014). A large number of scholars have described the morphological and histological changes of the digestive system during the early individual development of fish (Rønnestad et al., 2008; Zambonino-Infante et al., 2008; Teles et al., 2017). In the development of teleost fish, the basic mechanisms of organ and phylogeny are similar, but there are considerable interspecies differences in their differentiation, development, and functional relative time (Treviño et al., 2011; Fan et al., 2018). Therefore, it is necessary to conduct specific studies on the ontogenesis of the fish digestive system of some fishes to better understand their morphology and tissue physiology.

There are few studies on the digestive system of $P$. teira. In this experiment, the postembryonic development of the larval digestive system was observed to understand the occurrence and development of the larval digestive organs. To study the structural changes of the digestive tract tissue in its early development stage, and to provide a reference for the conversion of bait during the breeding of larvae.

\section{Spawning and breeding of larvae}

\section{Materials and Methods}

The fertilized egg of $P$. teira were collected from a single spontaneous spawning from a broodstock kept in captivity in the cage of the Tropical Fisheries Research and Development Centre, South China Sea Fisheries Research Institute, Chinese Academy of Fishery Science, Lingshui (Hainan, China). Fertilized eggs (approximately $1 \mathrm{~kg}$ ) are collected through the siphon method (Nuñez et al., 2008). Eggs were disinfected with 5\% povidone iodine for 4-6 min, then weigh and transferred to Semi-closed hatching net containing $10 \mathrm{~m}^{3}$ of water a density of $100 \mathrm{~g} / \mathrm{m} .16$ inflatable stones with a diameter of $2 \mathrm{~cm}$ were placed in the hatching net bag. The first hatchlings were hatched out under the conditions of $18 \mathrm{~h}$ and water temperature of $27 \pm 0.5^{\circ} \mathrm{C}$ (hatching rate $=84 \%$ ). The larvae are placed in hatching net bags for 3 days, during which time the water is not renewed until it is placed in the pond. The larvae are reared in the high pond for 30 days. During the experiment, the water temperature was $27-30^{\circ} \mathrm{C}$, salinity $30 \%$, dissolved oxygen $5.0-5.50 \mathrm{mg} / \mathrm{L}, \mathrm{pH} 8.2-8.4$, ammonia nitrogen content $<0.02 \mathrm{mg} / \mathrm{L}$, nitrite index $<0.005 \mathrm{mg} / \mathrm{L}$. S-type rotifer larvae were to larvae one times per day from 4 days post hatch until 8 days. The S-type rotifer was cultured as described by Leu et al (Leu et al., 2009). Cladocera and Copepod larvae were fed from 9 days to 15 days. Artificial compound feed was fed to larvae from 16 days to 30 days. Feeding ration was $8 \%$ of body weight, and particle size was adjusted during the growing period. 
Sample collections and processing

The experiment continued for $30 \mathrm{dph}$, and 30 larvae were collected every day from the first day of hatching until the end of the experiment. When taking samples, eugenol was used to anesthetize the larvae. After the larvae were completely anesthetized, the samples were collected in a sampling bottle containing paraformaldehyde solution, and the samples were stored in a refrigerator at $4{ }^{\circ} \mathrm{C}$ until they were used for histological research. The sample used is washed with running water for $12-15 \mathrm{~h}$, then dehydrated with 70\%-100\% gradient alcohol, 100\% xylene secondary transparent, embedded in liquid paraffin and cooled to a solid wax block, then $(5 \mu \mathrm{m})$ slice, HE staining, neutral resin sealing sheet. Observe and photograph stained sections of a German ZEIZZ optical microscope.

\section{Histological development of the digestive system of $P$. teira}

At $1 \mathrm{dph}$, the oral cavity and anus of the larvae are closed. The digestive tube is close to the abdominal wall. The yolk sac is basically intact and occupies most of the volume of the body cavity. The yolk sac stained with HE is dyed deep red. The esophagus is a straight tube with a mucosal layer of monolayers of cells, and no muscularis and goblet cells are observed (Figure 1A). At this time, the oropharyngeal cavity has formed, with a layer of oral mucosal epithelial cells, but not yet a muscle layer and submucosa. The stomach primordium is found to be a simple solid structure. The original structure of the stomach and intestine is not clearly distinguishable. The anus Not yet formed. In the $2 \mathrm{~d}$ larvae, the oral cavity and anus are still closed. As the larvae consume nutrients, the volume of the yolk sac decreases. On the side of the yolk sac, you can see that the esophagus is a simple short tube. At this time, the esophagus, oropharyngeal cavity, and gastrointestinal tract Not completely connected (Figure 1B). On the 3rd day, as the yolk sac is gradually absorbed by the larvae, the abdominal cavity of the larvae becomes larger, the esophagus begins to differentiate toward the pharyngeal region, the stomach at the end of the esophagus forms a gastric cavity, and the intestine is short with a mucosal layer and a single layer of columnar epithelium Cells (Figure 1C). On the 4th day, the eyes and mouth of the larvae were opened and started to feed, and entered the mixed nutrition stage. The oropharyngeal cavity is enlarged, and both the maxillary oral valve and the mandibular oral valve have appeared, and the upper jaw is longer than the lower jaw. The digestive tract develops gradually, the esophagus gradually enlarges and the esophagus wall gradually thickens, and the mucosal layer formed by cells on the esophagus is blurred. The oropharyngeal cavity, esophagus and stomach is connected. The structure of the stomach and intestine can be clearly distinguished, the differentiation of the stomach is not obvious, a certain volume has been formed inside, the mucosa layer is thin and the initial wrinkle structure is formed, the wrinkle is not obvious, the intestine is short and lacks goblet cells.

On the 5th day, the yolk sac of larvae completely disappeared, and each digestive tube further differentiated and entered the stage of exogenous nutrition. The esophagus is the most differentiated, and the mucosal layer of the esophagus is clear. A layered structure can be observed, including the mucosal layer, serous layer, and muscle layer. The length of the esophagus increases and extends to the stomach, and the mucosa is differentiated into stratified epithelium. There is a shallow crease at the junction of the esophagus and stomach, the volume in the stomach cavity becomes larger, and the intestine becomes longer and thicker to form an insignificant tortuous. The pyloric blind sac of the stomach begins to differentiate, and it will be divided into three parts: pyloric stomach, stomach body, and cardia stomach (Figure 1D). On the 7th day, the esophagus was increased in length, and no goblet cell differentiation was seen. It was able to distinguish circular and longitudinal muscle fibers, formed part of the esophageal mucosa, and a thin layer of connective tissue surrounding them. The stomach is still further differentiated, the boundary between the stomach, esophagus and intestine is obvious, and the number of mucosa is increased. The intestine extends further but still has no obvious tortuosity and lacks goblet cells (Figure 1E). On the 9th day, the initial mucosal folds appeared at the junction of the oropharyngeal cavity and the esophagus. A small amount of mucus cells and goblet cells were observed. From then on, the larynx cavity and the esophagus had almost no changes except for the continuous increase of cells (Figure 1F).

On the 12th day, the growth rate of larvae was accelerated, and the changes of the esophagus were particularly obvious. The longitudinal mucosal folds were formed, and the epithelial cells and goblet cells in the esophagus increased greatly. The thickness of the esophageal mucosa is obviously increased in the circular muscle layer, which is divided into the adventitia, muscle layer 
and submucosa. The differentiation between stomach body, pylorus, cardia, and caecum is obvious, in which the pylorus area and cardia area of the stomach are very short. The stomach body area occupies most of the stomach, and the boundary between these three parts is obvious, with longitudinal mucosal folds. The gastrointestinal wall has completed the submucosa, muscle layer and adventitia (Figure 1G). On the 14th day, the epithelial cells of the intestine have vacuole structure, and the mucosal folds are folded to a moderate degree, and the folds are obviously increased and widened (Figure 1H). On the 16th day, the intestine of the larvae was lightly stained, and the striated border could be seen. The number of mucosal folds increases and the mucosa thickens. The intestine is increased in length and formed obvious tortuosities, making the anterior, middle and posterior intestine zones obvious. There are some histomorphological differences between the foregut, midgut, and hindgut. The villi of the foregut are slender and abundant, with many goblet cells distributed on it. The folds of the foregut are longer than those of the midgut and hindgut. The larvae's stomach is beginning to differentiate into gastric glands and pyloric blind sacs. The lumen of the pyloric blind sac appears at the junction of the end of the pylorus and the front of the fore bowel. Mucosa folds appeared in the lumen and a few goblet cells were distributed. A large number of gastric glands are distributed in the stomach and the stomach glands are the most. The gastric gland is opened in a single shape in the gastric pits. The stomach is separated from the intestine by the pyloric sphincter, and the pylorus is rich in mucosal epithelial cells with a thick muscle layer (Figure 1I).
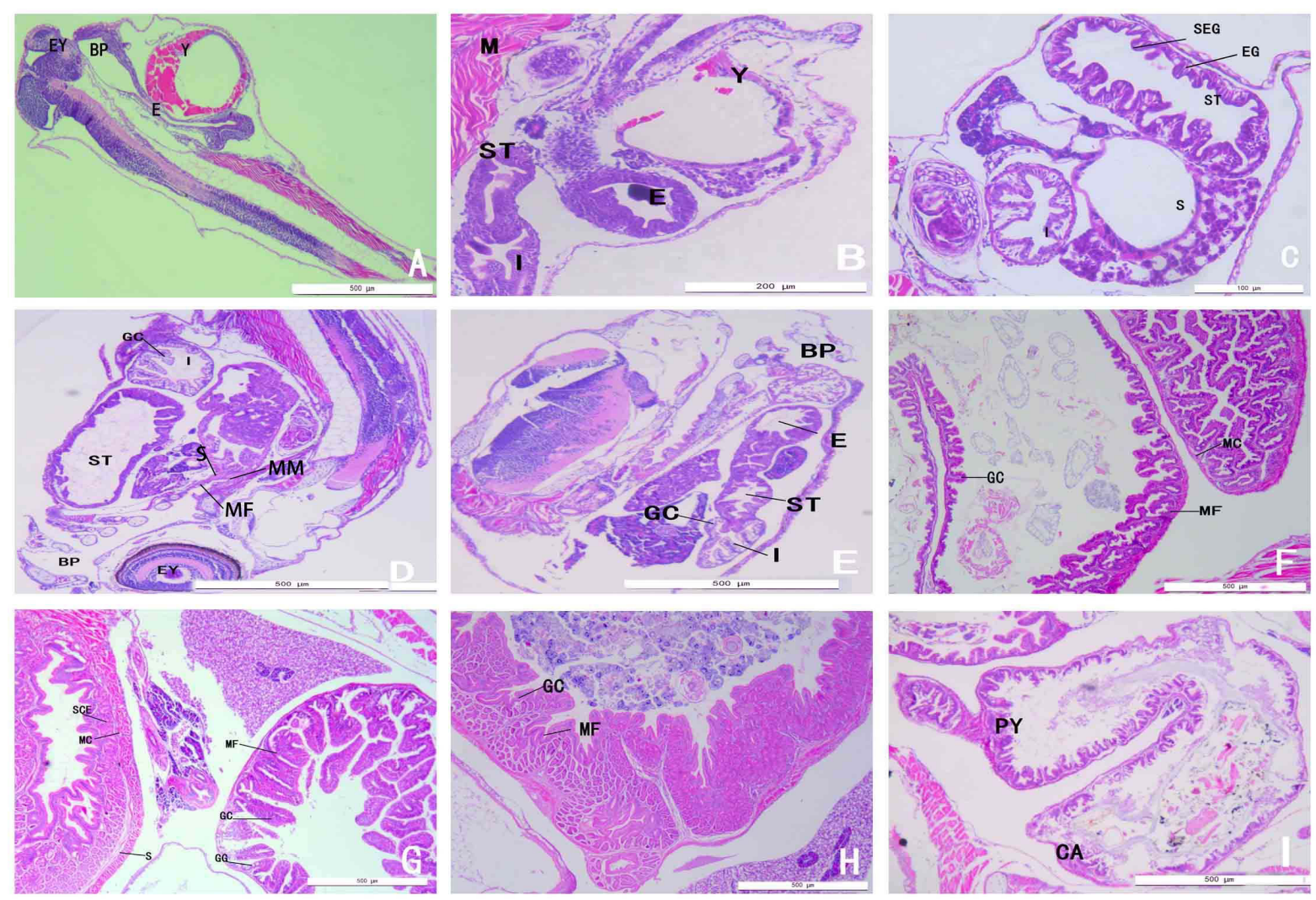

Figure 1 Histological observation of digestive tract of larvae of different days

A, 1d larvae whole longitudinal section; B, 2d larvae whole longitudinal section; C, 3d larvae whole longitudinal section; D, 5d larvae whole longitudinal section; E, 7d larvae whole longitudinal section; F, 9d larvae whole longitudinal section; G, 12d larvae whole longitudinal section; $H, 14 d$ intestinal cavity villous structure and goblet cell transverse section; $I$, 16d larvae gastric structure longitudinal section; BP, oropharyngeal cavity; CA, cardia; E, esophagus; EG, eosin Granules; EY, eye; GC, goblet cells; GG, gastric gland; I, intestine; LP, lamina propria; M, muscle tissue; MC, muscle layer; MF, mucosal folds; MM, Mucosal Muscle; N, notochord; PY, pylorus ; S, adventitia; SE, stratified epithelium; SEC, monolayer columnar epithelium; SM, submucosa; ST, stomach; Y, yolk sac. 
On the 17th day, the intestinal mucosa folds and upper cells became flat, and the intestine became longer and more curved. The number of mucosal folds and goblet cells increased significantly (Figure 2A). On day 20, the esophageal epithelium was covered with dense goblet cells, and the volume of mucosal folds became larger. The stomach further develops and the volume in the stomach cavity continues to expand, increasing the number of gastric glands. The pyloric caeca differentiate into more lumens, which become larger in volume and contain a large number of goblet cells (Figure 2B). The striae are found in the villi epithelium of the intestine. From 25 to 30 days, the structure of the digestive tract does not change much. During this period, due to the increase in the size of the juvenile, most changes in the digestive system are related to the complexity of the tissue and the size of the organ. Specifically, the number of mucosal folds and cells is increased in the esophagus and intestines, and the gastric glands and pits in the stomach increase (Figure 2C, Figure 2D).

At 30 days, mucus cells were distributed in large amounts in the esophageal mucosa and the thickness of the esophageal mucosa increased. Epithelial cells and goblet cells are increased in height in the esophagus, and the annular and longitudinal layers are thickened in the mucosa, and the degree of mucosal folds increases. The thickness of the fold is increased in the stomach cavity, and the thickness of the mucosal muscle layer and the lower layer is also increased. The staining of the mucosal layer is clearly distinguished, and the submucosa is slightly darker than the upper mucosa. The stomach has been developed to be more complete in structure and function. The number of gastric glands is extremely large, and gastric pits appear in the stomach wall, which has reached the structure of a fish stomach. The intestine is coiled and folded, the thickness of the muscle layer and the mucosal layer is increased, a large number of irregularly arranged goblet cells are distributed on the mucosa, and the number of intestinal folds increases. Since then, the intestinal tract is mainly reflected in changes in length and thickness, folds, and the number of cells (Figure 2E, Figure 2F).
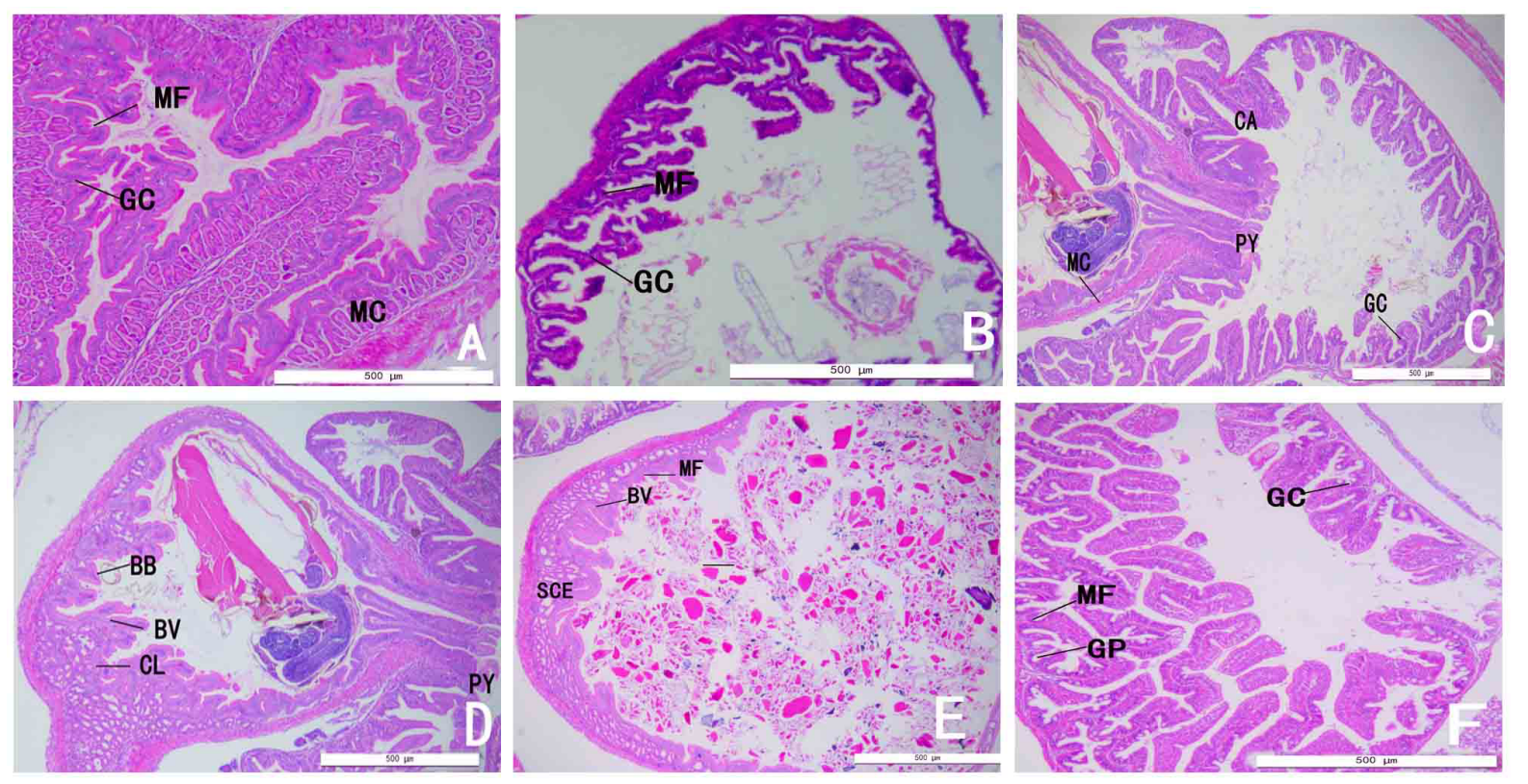

Figure 2 Histological observation of the digestive tract of larvae of different days

A, 17d larvae intestinal cavity longitudinal section; B, 20d larvae stomach longitudinal section; C, 25d larvae stomach and intestinal cavity longitudinal section; D, 25d larvae stomach and intestinal cavity longitudinal section; E, 30d larvae intestinal cavity longitudinal section; F, 30d larval stomach longitudinal section; $B B$, striated margin; $B V$, capillaries; $C A$, cardia; $C L$, central chylous duct; E, esophagus; EG, eosinophilic granules; EY, eye; GC, goblet cells; GG, gastric gland; I, intestine; LP, lamina propria; M, muscle tissue; MC, muscle layer; MF, mucosal folds; PY, pylorus; S, adventitia; SE, stratified epithelium; SEC, monolayer columnar Epithelium; SM, submucosa; ST, stomach. 


\section{Discussion}

Significance of studying the digestive system of $P$. teira

Studying the differentiation of the digestive tract and accessory glands during larval development is essential for synchronizing physiological development of feeding methods and feeding procedures (Lazo et al., 2011; Rønnestad et al., 2013), which is of particularly important for new aquaculture species. Although the basic mechanisms of larval digestive system development are not very different between marine teleosts, there are interspecies differences in the timing of different individual developmental events (Santamaria et al., 2004; Chen et al., 2006). This is related to different biological and abiotic feeding factors, and different breeding methods between species (Treviño et al., 2011). Many scholars have studied the development of the digestive system of marine teleost fish, including Seriola lalandi (Chen et al., 2006), Pseudosciaena crocea (Mai et al., 2005), Atractoscion nobilis (Galaviz et al. 2011), and Argyrosomus regius (Solovyev et al. 2016). This is the first study on the histology of the development of the digestive system of $P$. teira. Studying the development process of the digestive system of $P$. teira helps to discover its feeding rules and understand the nutritional changes during its development, which plays an important role in the breeding of larvae.

\section{Morphological characteristics of the early development of the digestive system of $P$. teira}

Like most fish, the development of the digestive system of $P$.teira can be roughly divided into three stages: endogenous nutrition stage, mixed nutrition stage and exogenous nutrition stage (Kozaric et al., 2008; Wegner et al., 2009; Yang et al., 2010; Saelee et al., 2011; Pradhan et al., 2012). The period of $P$. teira and Oplegnathus fasciatus is the same in the endogenous trophic stage (Ou et al., 2015), starting from the initial hatchling to the end of 3d. At this stage, the mouth of the larvae is still closed and the digestive system is not differentiated. The digestive tract is linear, and there is no feeding ability. During the period, the nutrition of the larvae is provided by the yolk sac and oil balls. Different fish are in different periods of mixed nutrition. Barracudas spend 5-7 days in mixed nutrition (Nie et al., 2016), while Acanthopagrus latus (Wang et al., 2012) directly enter exogenous nutrition. It does not go through the mixed nutrition stage. From the 4th to the 5th day, $P$. teira is in the mixed nutrition stage, at this time the digestive system has just started to develop, and the digestive function is imperfect. The larva grows relatively slowly. On the 4th day, the eyes and mouth were opened, and the mouth and esophagus were just beginning to communicate. At this time, the larvae have a certain swimming ability and start to take the initiative to eat, but the food is eaten small and less, and the digestion ability is poor. It is the first critical period of artificial nursery. The yolk sac and food is each provided with a portion of the nutrients, and the larvae are provided with suitable bait as an important factor in survival. From the 6th day, the digestive system develops further, the digestive organs become more complex, and enter the stage of exogenous nutrition. At this stage, the larvae gradually strengthen their swimming ability to eat more and bigger food. Food is provided with all the nutrients needed for growth and development. The oropharyngeal cavity, esophagus, stomach, and intestines gradually developed completely, and finally reached a structure similar to that of adult fish. It shows that the feeding, growth and morphological development of $P$. teira are consistent with the development of the digestive system.

\section{Feeding of $P$. teira adapts to the development of digestive system}

The developmental stage of the digestive system is compatible with its function and structure. Different fish have different digestive characteristics. Hippocampus kelloggi does not have the yolk sac to provide the endogenous nutritional stage of full nutrition, but directly enter the mixed nutritional period (Lin et al., 2008). This reason is due to the reproductive method of ovoviviparity and the larvae already have relatively complete digestive organs and feeding ability in 1-2 days. Research showed that the Hucho taimen, as a fierce carnivorous fish, broke its membrane 30 days after fertilization (Guan et al., 2007). It takes 24 days of endogenous nutrition period until 30 days before entering the complete exogenous nutrition period. $P$. teira is different from $H$. kelloggi and $H$. taimen. The larval fish has a simple digestive tract structure with poor digestive energy in the first 3 days. The powerful nutrients are only provided by the yolk sac, which is the endogenous nutrition stage. Then on the 4 th to 5 th days, it goes through a short-mixed nutrition stage and completely enters the exogenous nutrition stage. 
The type of food that the larvae of $P$. teira are consistent with the development of the internal digestive system. There must be certain developmental changes in the structure of the digestive tract to meet its survival needs. Rotifers are fed to larvae in the early stages, then copepods and cladocerans are gradually fed to them, and finally larvae are domesticated to eat artificial compound feed. The reason for the feeding strategy is that the early larvae have a small mouth, poor swimming and feeding ability, and weak digestive ability. Then the digestive system continues to develop, the structure and function of the digestive tract are constantly improved, and the feeding and digestive capabilities are enhanced. The appearance of esophageal mucosal folds increases the area of contact with food, while increasing the volume of the esophagus encourages fish to eat more food. The differentiation of the stomach body, pyloric stomach, and cardia stomach makes the division of the stomach clearer, the function is more complete, and the digestion efficiency is higher. The enlargement of the pyloric blind sac is more conducive to digestion and absorption. The intestine increases the food contact area by bending and folding, and the mucosal folds and goblet cells increase in number. These structural changes all increase the rate of food digestion and absorption.

\section{Acknowledgments}

This study was supported by the Financial Fund of Ministry of Agriculture and Rural affairs of China (NHYYSWZZZYKZX2020), Key Special Project for Introduced Talents Team of Southern Marine Science and Engineering Guangdong Laboratory (Guangzhou) (GML2019ZD0605), China-ASEAN maritime cooperation fund (00-201620821), the Guangdong Provincial Science and Technology Project (2019B030316030) and Fund of Key Laboratory of South China Sea Fishery Resources Exploitation and Utilization, Ministry of Agriculture and Rural Affairs(FREU2018-01) and Key Laboratory of Healthy Mariculture for the East China Sea, Ministry of Agriculture and Rural Affairs (2020ESHML09).

References
Bai M., 2009. Marine ornamental fish. chemical industry press.
Chen B.N., Qin J.G., Kumar M.S., Hutchinson W. and Clarke S., 2006. Ontogenetic
development of the digestive system in yellowtail kingfish seriola lalandi larvae. Aquaculture,
256(1-4): 0-501. http://dx.doi.org/10.1016/j.aquaculture.2006.01.041 Fanfan S., Caijuan L., Teng T., Yining C., Jinqiang G. and Chuankun Z., 2018. Ontogenetic development of digestive tract and digestive enzymatic activities in, Squaliobarbus curriculus, larvae. Aquac Res, 49(9): 3158-3166. https://doi.org/10.1111/are.13779

Galaviz M.A., García-Gasca A., and Drawbridge M., 2011. Ontogeny of the digestive tract and enzymatic activity in white seabass, Atractoscion nobilis, larvae. Aquaculture, 318: 162-168. https://doi.org/10.1016/j.aquaculture.2011.05.014

Gisbert E., Ortiz-Delgado J.B. and Sarasquete C., 2008. Nutritional cellular biomarkers in early life stages of fish. Histol Histopathol, 23: 1525-1539. doi: 10.14670/HH-23.1525

Gisbert E., Morais S. and Moyano F.J., 2013. Feeding and digestion. In Larval fish aquaculture (ed. JG Kim), pp. 73-123. Nova Publishers, New York.

Gisbert E., Moreira C., Castro-Ruiz D., ztürk S., Fernández C. and Gilles S., 2014. Histological development of the digestive system of the amazonian pimelodid catfish Pseudoplatystoma punctifer. Animal, 8(11): 1765-1776. doi: 10.1017/S1751731114001797

Cuenca-Soria C.A., álvarez-González C.A., Ortiz-Galindo J.L., Tovar-Ramírez D., Guerrero-Zárate R., and Aguilar-Hernández S., 2013. Histological development of the digestive system of mayan cichlid, cichlasoma urophthalmus, (günther 1862). J Appl Ichthyol, 29(6): 1304-1312. https://doi.org/10.1111/jai.12307

Golani D., Sonin O. and Edelist D., 2011. Second records of the Lessepsian fish migrants Priacanthus sagittarius and Platax teira and distribution extension of Tylerius spinosissimus in the Mediterranean. Aquat Invasions, 1: 7-11. DOI: 10.3391/ai.2011.6.S1.002

Guan H.H., Kuang Y.Y. and Xu W., 2007. Histological observation of the development of the digestive system organs of the Hucho taimen. Chinese J Zool, 42 (2): 116-123.

Lazo J.P., Darias M.J. and Gisbert E., 2011. Ontogeny of the digestive tract. In: Larval fish nutrition, 1st edn. G. J. Holt (Ed.). Wiley \& Sons, Inc., Chichester, UK, pp. 5-46.

Leu M.Y., Liou C.H., Wang W.H., Yang S.D. and Meng P.J., 2009. Natural spawning, early development, and first feeding of the semicircle angelfish Pomacanthus semicirculatus (Cuvier, 1831 ) in captivity. Aquac Res, 40: 1019-1030. DOI: 10.1111/j.1365-2109.2009.02192.x 
Leu M.Y., Tai K.Y. and Meng P.J., 2018. Embryonic, larval and juvenile development of the longfin batfish, Platax teira, (Forsskăl, 1775) under controlled conditions with special regard to mitigate cannibalism for larviculture. Aquaculture, (493): 204-213. https://doi.org/10.1016/j.aquaculture.2018.05.006

Liao J., 2018. Artificially bred the longfin batfish Platax teira with high cost performance and can be fed with artificial compound feed for ornamental consumption. Oceans and fisheries, 11: 62-63. Lin Q., Lu J.Y, and Zhang B., 2008. Morphological and histological study of post-embryonic development of the digestive system of the Hippocampus kelloggi. Journal of Tropical Oceanography, 26(6): 46-51.

Kozaric Z., Kuzir S., Petrinec Z., Gjurcevic E. and Bozic M., 2008. The development of the digestive tract in larval European catfish (Silurus glanis L.). Anat Histol Embryol, 37: 141-146. https://doi.org/10.1111/j.1439-0264.2007.00812.x

Mai K., Yu H., Ma H., Duan Q., Gisbert E., Zambonino Infante J. and Cahu C., 2005. A histological study on the development of the digestive system of Pseudosciaena crocea larvae and juveniles. J Fish Biol, 67:1094-1106.

Nie G.F., Li J., Ou Y.J., Tang Q.L., Wu S.Q., Wang P.F. and Wen J.F., 2016. Histological observation of post-embryonic development of the digestive system of barracuda, juvenile and juvenile fish. Chinese Fisheries Science, 23(1): 90- 103.

Nuñez J., Dugué R., Arana, N.C., Duponchelle, F. and Legendre, M., 2008. Induced breeding and larval rearing of surubí, Pseudoplatystoma fasciatum (linnaeus, 1766), from the bolivian amazon. Aquac Res, 39(7): 764-776.

Ou Y.J., Li J.E. and Ai L., 2015. Histology of Digestive System in Early Development Stage of Oplegnathus fasciatus. Journal of South China Agricultural University, 36(01): 23-27.

Portella M.C., Jomori, R.K., Leit O.N.J., Menossi O.C.C., Freitas T.M. and Kojima J.T., 2014. Larval development of indigenous south american freshwater fish species, with particular reference to pacu (Piaractus mesopotamicus): a review. Aquaculture, 432: 402-417.

Pradhan P.K., Jena J.K., Mitra G., Sood N. and Gisbert E., 2012. Ontogeny of the digestive tract in butter catfish Ompok bimaculatus (Bloch) larvae. Fish Physiol Biochem, 38: 1601-1617.

Rønnestad I. and Morais S., 2008. Digestion. In: Fish larval physiology. R. N. Finn, B.G. Kapoor (Eds). Science Publishers, Enfield, pp. 201-262.

Rønnestad I., Yúfera M., Ueberschär B., Ribeiro L., Sæle Ø. and Boglione C., 2013. Feeding behaviour and digestive physiology in larval fish: current knowledge, and gaps and bottlenecks in research. Rev Aquacult. 5:S59-S98. https://doi.org/10.1111/raq.12010

Saelee T., Kiriratnikon S., Suwanjarat J., Thongboon L. and Pongsuwan K., 2011. The development of the digestive system in Clarias nieuhofii Larvae: histology and histochemical studies. J Microsc Soc Thailand, 4: 16-19.

Santamaria C.A., Marín De Mateo M. and Traveset R., 2004. Larval organogenesis in common dentex Dentex dentex L. (Sparidae): histological and histochemical aspects. Aquaculture, 237: 207-228. doi:10.1016/j.aquaculture.2004.03.020

Solovyev M.M., Campoverde C. and Öztürk S., 2016. Morphological and functional description of the development of the digestive system in meagre (Argyrosomus regius): an integrative approach. Aquaculture, 464:381-391. http://dx.doi.org/10.1016/j.aquaculture.2016.07.008

Teles A., Salas-Leiva J., Alvarez-González C.A., Gisbert, E., Ibarra-Castro L. and Urbiola J.C.P., 2017. Histological study of the gastrointestinal tract in longfin yellowtail (Seriola rivoliana) larvae. Fish Physiol Biochem, 43(6): 1613-1628. DOI: 10.1007/s10695-017-0397-5

Trevino L., Alvarez-Gonz-alez C.A., Perales-Garcia N., ArevaloGalan L., UscangaMartınez A., Marquez-Couturier G., Fernandez I., Gisbert E., 2011. A histological study of the organogenesis of the digestive system in bay snook Petenia splendida Gunther (1862), from hatching to the juvenile stage. J Appl Ichthyol, 27: 73-82. https://doi.org/10.1111/j.14390426.2010.01608.x

Wang Y.C., Li J.E., Ou Y.J. and Su H., 2012. Histological observation of digestive tract of Acanthopagrus latus, juvenile and juvenile fish. Journal of Southern Agriculture, 43(08): 12121217.

Wegner A., Ostaszewska T. and Rozek W., 2009. The ontogenetic development of the digestive tract and accessory glands of sterlet (Acipenser ruthenus L.) larvae during endogenous feeding. Rev Fish Biol Fish, 19: 441-444. https://doi.org/10.1007/s11160-009-9111-8

Yang R., Xie C., Fan Q., Gao C. and Fang L., 2010. Ontogeny of the digestive tract in yellow catfish Pelteobagrus fulvidraco larvae. Aquaculture, 302: 112-123. 
http://dx.doi.org/10.1016/j.aquaculture.2010.02.020

Zambonino-Infante J., Gisbert E. and Sarasquete C., 2008. Ontogeny and physiology of the digestive system of marine fish larvae. In: Feeding and digestive functions of fish. J. E. O. Cyrino, D. Bureau, B. G. Kapoor (Eds). Science Publishers Inc, Enfield, pp. 277-344. 